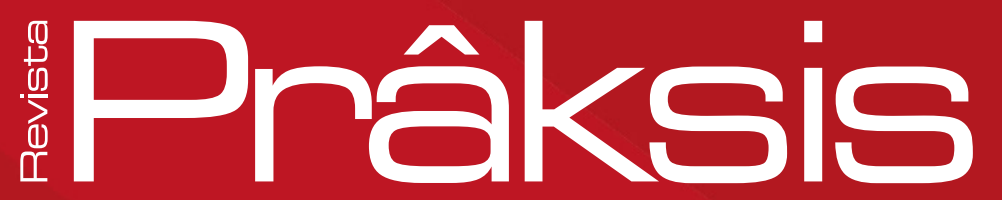

p-ISSN: 1807-1112

e-ISSN: 2448-1939 Aprovado em: 15 de dezembro de 2018 Sistema de Avaliação: Double Blind Review RPR |a. 16 | n. 1 | p. 144-168|jan./abr. 2019

DOl: https://doi.org/10.25112/rpr.v1i0.1776

\title{
A LEI 10.639/2003 NA FORMAÇÃO DE PROFESSORES: 0 DISCURSO JuRídico, político e pEDAGócico
}

LAW 10.639/2003 ON TEACHER TRAINING: LEGAL, POLITICAL AND PEDAGOGICAL DISCOURSE

\section{Eliane Anselmo}

Doutora em Educação pela Universidade Federal do Rio Grande do Sul (Porto Alegre/Brasil). Professora aposentada da rede municipal de ensino (Novo Hamburgo/Brasil).

E-mail: elianeanselmo@uol.com.br. 


\section{RESUMO}

0 presente artigo traz algumas problematizações sobre a formação de professores, a partir da Lei 10.639/2003, de modo mais específico, do Cap. 5 da tese de doutorado da autora. Destaca-se, então, o entendimento da legislação como uma prática que legitima as ações do governo, a consolidação de políticas de ações afirmativas para a Educação, e também a formação de professores, considerada uma prática conformada pelos discursos governamentais (dentre eles, as estatísticas). Tais aspectos são exibidos a partir de um breve exame da legislação, de documentos e materiais pedagógicos emitidos pelo Ministério da Educação e parcerias, de programas e processos de formação de professores ofertados pela Universidade Federal do Rio Grande do Sul (UFRGS), através do Departamento de Educação e Desenvolvimento Social (DEDS).

Palavras-chave: Legislação. Ações afirmativas. Lei 10.639/2003. Formação de professores. Discursos e práticas.

\section{ABSTRACT}

This article brings some problematizations about teacher training, from Law 10.639/2003, more specifically, from Chapter 5 of the author's doctoral thesis. It stands, then, the understanding of legislation as a practice that legitimizes government actions, the consolidation of affirmative action policies for Education, and teacher training, which is considered as a practice conformed by governmental discourses (among them, the Statistics). These aspects are presented through a brief examination of the legislation, documents and teaching materials issued by the Ministério da Educação and partnerships, programs and teacher training processes offered by the Universidade Federal do Rio Grande do Sul (UFRGS), by means of the Departamento de Educação e Desenvolvimento Social (DEDS).

Keywords: Legislation. Affirmative actions. Law 10.639/2003. Teacher training. Discourses and practices. 


\section{PARA INÍCIO DE CONVERSA}

A publicação daLei 10.639/2003, quealterou artigos daLeide Diretrizes e Bases daEducação(LDBEN/1996), trouxe a questão étnico-racial, relacionada à história da África, do povo negro e afrodescendente, para o currículo escolar da educação básica brasileira. Neste período, a autora já atuava como integrante da equipe técnico-pedagógica da Secretaria Municipal de Ensino de Novo Hamburgo (SMED), onde ficou nítido que tal legislação causou polêmica e preocupação. Como poderia ser implementada essa temática no currículo escolar se os professores a desconheciam, na medida em que ela não era contemplada no currículo de formação de professores? E, assim, como ela poderia ser trabalhada em sala de aula?

Após um longo período de trabalho dedicado à formação de professores, aos estudos sobre o tema, e à militância no Movimento Negro local, a autora participou da soma de esforços para a implementação da Lei 10.639/2003 nas escolas da rede municipal de ensino. Em 2010, com o ingresso no Programa de Pós-Graduação da Universidade Federal do Rio Grande do Sul (UFRGS), definiu a formação de professores como tema central da sua tese de doutorado. É importante salientar que a pesquisa foi inscrita no campo das Políticas Públicas de Formação de Professores, focalizando a educação étnico-racial. Desse modo, a questão central para essa problematização é como o discurso da formação de professores para a educação étnico-racial se constituiu historicamente, e quais os efeitos que ele produz.

Ao problematizar a formação de professores para educação étnico-racial, é necessário definir os elementos que irão constituir o problema, e a quais soluções distintas procuram responder. De acordo com Rabinow (1999), "o pensamento é a liberdade com relação ao que se faz, o movimento pelo qual se toma distância deste 'fazer', constituindo-o como objeto e refletindo sobre ele como problema" (p. 24). Assim, "dizer que o estudo do pensamento é a análise de uma liberdade não significa que se esteja lidando com um sistema formal, cuja única referência é ele mesmo" (p. 25). Ao contrário, está-se lidando com um campo de ação, um comportamento, uma prática.

Desse modo, foi necessário um estranhamento, outro olhar para a questão da formação de professores, questionar o que se tornou óbvio, naturalizado nessa minha trajetória de mulher negra e pedagoga! Não se trata, simplesmente, de discutir se o professor está ou não preparado para tal prática, se cabe ou não a ele abordar a temática étnico-racial na escola, ou definir qual o melhor modo de ofertar essa formação específica. Aqui, é preciso tratar da questão com suas implicações efetivas.

Considerando-se a perspectiva de análise para fins deste estudo, cabe refletir sobre esta afirmação, tomando o censo demográfico como um mecanismo de governo, que também participa da produção e disseminação de verdades sobre a questão racial no Brasil. Assim, entende-se que a organização, a aplicação, a análise, e a divulgação dos dados são etapas que selecionam, nomeiam, classificam e hierarquizam os indivíduos, fixam seus lugares; portanto, discriminam (ANSELMO, 2003). 
Com a obrigatoriedade de tratar a questão étnico-racial no currículo escolar, o governo decretou uma urgência no nível das mantenedoras dos sistemas de ensino para oferecer a formação continuada específica aos professores. Na legislação educacional, determinou-se o reconhecimento dos direitos da população negra, afro-brasileira e indígena. Desse modo, questiona-se: como foi introduzido esse discurso para erradicar o preconceito e a discriminação racial na formação de professores? Quais as efetivas implicações nas mudanças que agora estão ocorrendo, seja na ou com a formação de professores e sua relação com as práticas escolares?

Diante disso, pode-se perguntar: como se instituiu, na atualidade, a ideia de formação para a educação étnico-racial? Que discurso legitima o processo atual de "formação continuada" e suas diferentes significações no contexto educacional brasileiro, considerando-se os pressupostos da educação para a igualdade e contemplando a diversidade da população, colocados pelo Ministério de Educação e Cultura (MEC)?

Tais diretrizes partem do princípio de que o professor precisa apropriar-se dos conhecimentos sobre as culturas negra e indígena para ensiná-los na escola. Nesse sentido, nas discussões sobre os problemas da qualidade do ensino, a formação de professores passa a ser a questão de maior visibilidade na tentativa de assegurar a igualdade racial apontada na constituição de 1988? É importante reafirmar o discurso de mudanças sociais via escola? Tais aspectos pressupõem que um professor com ampla capacitação sobre as questões do negro e do índio seja capaz de minimizar ou erradicar as questões de preconceito e discriminação? Quais são as condições de possibilidade da formação docente diante do desafio que lhes é imposto a nível governamental pelas atuais políticas públicas de combate à discriminação e ao preconceito? Pressupõe-se que, a partir de uma dada formação específica, o professor seja capaz de transformar o aluno e a realidade que o cerca. Depois de tais questionamentos, analisa-se o tema nas seguintes perspectivas:

\section{MODO COMO A LEGISLAÇÃO, ENQUANTO PRÁTICA DE INCLUSÃO JURÍDICA, LEGITIMA AS AÇÕES DO GOVERNO}

\subsection{DO JURÍDICO}

Há mais de quatro décadas foi criado o Dia Internacional de Luta pela Eliminação da Discriminação Racial, pela Organização das Nações Unidas (ONU), celebrado no dia 21 de março de cada ano, em 
referência ao Massacre de Sharpeville', na África do Sul. A data foi criada após o episódio de protesto contra uma lei - A Lei do Passe, e chamou a atenção mundial pelo alto grau de segregação racial existente naquele país. Desde então, as discussões sobre raças, racismos e direitos humanos voltaram a ganhar relevância. No Brasil, ressalta-se que apenas depois do processo de redemocratização, cujo marco jurídico foi a Constituição de 1988, a noção de direitos humanos passou a se vincular a diferentes lutas: contra a tortura; contra os abusos policiais, em nome da manutenção da ordem; contra a censura; pela revisão da Lei da Anistia; e pelos direitos das mulheres e das minorias. Com a retomada da luta pelos direitos humanos, houve a reorganização das entidades negras, e as reivindicações contra a discriminação passaram a ocupar cada vez mais lugar no debate público brasileiro e na pesquisa acadêmica.

A partir de 1992, a criação de Comissões de Combate ao Racismo, no âmbito dos sindicatos e das centrais sindicais, foi um dos efeitos do reconhecimento dessas reivindicações. Nos últimos anos, em especial a partir da III Conferência Mundial contra o Racismo, Discriminação Racial, Xenofobia e Intolerâncias Correlatas, realizada em Durban - África do Sul, em 2001 (da qual o Brasil fez parte), houve, efetivamente, um aumento das discussões acerca da dinâmica das relações raciais no Brasil, especialmente das diversas formas de discriminação racial vivenciadas pela população negra. Os países participantes foram estimulados a "coletarem, compilarem, analisarem, disseminarem e publicarem dados estatísticos confiáveis, em nível local e nacional, relativos a indivíduos e membros de grupos e comunidades sujeitos à discriminação" (FUNDAÇÃO PALMARES, 2007). As frentes do Movimento Negro, tanto em âmbito nacional quanto internacional, passaram a cobrar ações governamentais que cumprissem os compromissos assumidos pelos países participantes.

No Brasil, bem antes disso, ocorreram mudanças no campo jurídico, quando foi instituída a criminalização constitucional do racismo, na Lei 7716/1989, conhecida como Lei Caó. A partir de então, surgiram novas legislações: o Decreto 4887/2003, que garante a titularização das terras remanescentes de quilombos²; a criação da Secretaria Especial de Promoção da Igualdade Racial (SEPPIR), em 2003; o decreto que estipula o dia 13 de maio (Dia da Abolição da Escravatura), como o Dia Nacional de Combate ao Racismo; a Lei 10639/2003, que inclui, nos currículos escolares, a "História e Cultura Afro-Brasileira";

\footnotetext{
1 As pessoas protestavam contra a Lei do Passe, que obrigava negros e negras a andarem com cartões de identificação que estabeleciam locais nos quais podiam ou não passar e/ou frequentar. Os homens, mulheres e crianças que foram massacrados (69 mortos e 186 feridos) pela polícia, realizavam um protesto pacífico.

2 Para o Instituto Socioambiental (ISA), o reconhecimento territorial é um passo importante na luta pela titulação da terra, quando o Estado reconhece que o território existe, e que a comunidade que lá vive tradicionalmente ocupa e usa o espaço territorial, ligado às suas tradições e ancestralidade.
} 
a Lei $n^{\circ}$ 12.519, de 10 de novembro de 2011, que institui o dia 20 de novembro como Dia Nacional de Zumbi e da Consciência Negra; e a aprovação do Estatuto da Igualdade Racial.

Assim, a partir dessas determinações legais e de numerosas reuniões, o Movimento Negro e o Estado brasileiro elaboraram, conjuntamente, uma ampla agenda de reparações coletivas, sendo que a questão racial é incluída como prioridade na pauta de políticas públicas do país, consolidada com a criação da SEPPIR, em 2003, pelo então presidente Lula.

Dessa forma, ficou estabelecido um modo de intervenção do Estado para toda uma população, agora "apartada" por raça/cor, conforme as estatísticas oficiais. Na área da educação, as reformas exigidas pela Lei de Diretrizes e Bases da Educação Nacional (LDB/1996) trouxeram consigo um movimento ambivalente: das demandas voltadas à democratização da educação, e das reformas educacionais pautadas pela noção de equidade social (SOUZA, 2007, p. 100). Portanto, o art. $3^{\circ}$ da Lei 9394/96, coerente com o texto constitucional de 1988, arrola os princípios que dão forma ao ordenamento jurídico na educação nacional, isto é, define as bases sobre as quais o ensino será ministrado. 0 mesmo texto estabelece que: "A formação deve reconhecer os direitos humanos, em especial das minorias ${ }^{3}$ e ainda reconhece a existência do multiculturalismo" e "a vinculação entre a educação escolar, o trabalho e as práticas sociais". Já o art. $61^{\circ}$ obriga "a capacitação em serviço que permita a formação permanente, aperfeiçoamento constante, podendo ser realizado na modalidade de ensino à distância, sendo responsabilidade do sistema de ensino e da instituição onde atua o professor".

Sendo assim, a formação de professores é direcionada para o reconhecimento da diversidade étnicoracial brasileira, destacando-se a pluralidade cultural da nação e a importância de seu tratamento no âmbito da escola, através da sua incorporação ao currículo escolar. A Lei 10.639/2003 alterou a LDB, com o acréscimo dos seguintes artigos: 26-A (que estabelece as diretrizes e bases da educação nacional, para incluir, no currículo oficial da rede de ensino, a obrigatoriedade da temática: "História e Cultura Afro-Brasileira"); e 79-B (que inclui, no calendário escolar, o "20 de novembro", como o Dia Nacional da Consciência Negra). Posteriormente, com a publicação da Lei n 11.645, de 10 de março de 2008, ocorreu outra alteração, com a inserção do estudo da questão indígena. 0 art. 26-A da LDB passou a vigorar com a seguinte redação:

Nos estabelecimentos de ensino fundamental e de ensino médio, públicos e privados, torna-se obrigatório o estudo da história e cultura afro-brasileira e indígena. § 10 O conteúdo programático a que

\footnotetext{
${ }^{3}$ Para Poutignat (1998), o termo 'minorias' era uma das concepções adotadas pela sociologia americana para "etnicidade", entendida como "característica de um grupo minoritário definido por traços culturais específicos", "subgrupos residuais", às margens da sociedade (p. 80).
} 
se refere este artigo incluirá diversos aspectos da história e da cultura que caracterizam a formação da população brasileira, a partir desses dois grupos étnicos, tais como o estudo da história da África e dos africanos (sic!), a luta dos negros e dos povos indígenas no Brasil, a cultura negra e indígena brasileira, e o negro e o índio na formação da sociedade nacional, resgatando as suas contribuições nas áreas social, econômica e política, pertinentes à história do Brasil. § 2o Os conteúdos, em especial nas áreas de educação artística e de literatura e histórias brasileiras (referentes à história e cultura afro-brasileira e dos povos indígenas brasileiros), serão ministrados no âmbito de todo o currículo escolar, em todo o país (BRASIL, 1996. Acréscimo meu).

Em um artigo sobre a Lei 10.639/2003, Sales (2005) critica a falta de extensão da legislação para os cursos de graduação e licenciatura:

[...] a Lei Federal, simultaneamente, indica uma certa sensibilidade às reivindicações e pressões históricas dos movimentos negro e anti-racistas brasileiros, como também indica uma certa falta de compromisso vigoroso com a sua execução e, principalmente, com sua a eficácia, uma vez que não estendeu aquela obrigatoriedade aos programas de ensino e/ou cursos de graduação, especialmente os de licenciatura, das universidades públicas e privadas, conforme uma das reivindicações da Convenção Nacional do Negro pela Constituinte, realizada em Brasília-DF [...] (BRASIL, 2003, p. 35).

Além disso, reafirma a necessidade de pressão sobre os governos, nos âmbitos federal, estadual e municipal, para que a lei, de fato, seja cumprida, e "não se transforme em letra morta do nosso sistema jurídico" (BRASIL, 2003, p. 35). Aqui, destaca-se que, da implantação da Lei 10.639, em 2003, até a criação da Lei 11.645, em 2008, ocorreu uma espécie de "esquecimento" na legislação educacional, em relação à questão indígena. "Esquecimento" semelhante ocorreu no Censo Demográfico, realizado pelo IBGE, em 1990-91. Dessa maneira, a inclusão dos indígenas, como uma das classificações para identificar os tipos raciais, se deu tardiamente, sendo o último grupo a ser incluído no Censo, antecedido, até mesmo, pelos amarelos. Como esse discurso da lei, voltada à educação das relações étnico-raciais, captura os professores subjetivados pelos números das estatísticas e dos indicadores econômicos e sociais de uma população identificada por raça e cor? Sem dúvida, o modo como se apresenta a estrutura dos cursos de formação continuada de professores voltados à questão étnico-racial, com todas as suas implicações nas discussões de raça e racismo, de preconceito e discriminação racial e das relações raciais, produzem uma forma de dar visibilidade à população negra e parda.

O governo, ao intervir na escola - via ordenação do currículo escolar e da formação de professores -, visa concretizar seu projeto nacional de inclusão social na dimensão étnico-racial. É o arcabouço jurídico com suas leis, resoluções, pareceres e diretrizes que legitimam essa intervenção. Assim, consolida-se 
uma prática jurídica de inclusão, com os preceitos de igualdade e da educação como um direito social, contidos na Constituição Federal. Recentemente, em novembro de 2014, foi aprovado por unanimidade, na Comissão de Cultura da Câmara dos Deputados, o Projeto de Lei $n^{\circ}$ 6.787, de 2013, de autoria do Deputado Renato Simões, que altera a Lei $n^{\circ} 662$, de 6 de abril de 1949, para incluir o dia 20 de novembro - Dia Nacional de Zumbi e da Consciência Negra - nos feriados nacionais (CEERT, 2014, p. 1). Até agora, 1/6 dos municípios do país já aderiram ao feriado. A presidente da Comissão de Cultura, deputada baiana Alice Portugal, também se manifestou positivamente a respeito do projeto de Renato Simões: "É muito importante que a Câmara dos Deputados sinalize para a sociedade brasileira que nós somos defensores do processo de igualdade. A discriminação precisa ser combatida" (CEERT, 2014, p. 1).

A forma de proteção legal, a partir do momento em que é especificada para a população negra e indígena, também produz negros e indígenas como sendo diferentes dos demais cidadãos - dos "autênticos" cidadãos brasileiros brancos, de origem europeia. Desse modo, demarca-se a questão racial no país. A população mostrada pelos dados estatísticos e, portanto, oficializada pelos números, é uma população identificada pela cor/raça, tornando-se, assim, uma população "racializada", na interpretação de Magnoli (2009). Nesse sentido, a formação de professores, determinada pelo Governo Federal, também participa da produção, no âmbito escolar, dessa racialização.

\subsection{DO POLITICO}

Quando o governo incorporou à sua prática política da inclusão social a dimensão étnico-racial, a meta de diminuição das desigualdades sociais passou a ser também a de diminuição das desigualdades raciais. Incluir negros, pardos e indígenas remete à ideia de trazer para, buscar, acomodar, agregar quem está à margem, os diferentes, os excluídos; é preciso dar-lhes visibilidade junto aos demais - no caso, os brancos. Para tal, torna-se imprescindivel legitimar essa visibilidade - cria-se uma legislação específica para a população negra, parda e indígena; decreta-se, ainda, a urgência de políticas de formação de professores, via legislação educacional.

Nesse cenário, o discurso da inclusão social e racial (adotado pelo governo) emerge baseado nos princípios de igualdade e justiça - sendo que a igualdade, via de regra, é tomada como sinônimo de equidade. No entendimento de Silva Junior (2001), no entanto, a equidade precede a igualdade, pois o princípio da equidade é "tratar de forma desigual os desiguais sem que se eternizem as diferenças" ( $p$. 310). Nesse sentido, "a equidade é que leva à igualdade; estas são duas linhas que convergem para um só lugar: a inclusão" (p. 311). O governo, ao fazer uso de certos mecanismos, como campanhas, políticas públicas, documentos oficiais, estatísticas, enfim, um conjunto de estratégias do Estado, determina 
quem, quando, onde e como as coisas devem acontecer. Trata- se de um modo de gerenciar determinada parcela da população (onde negros e pardos recebem a concessão de benefícios do bem público como forma de inclusão social e racial). Aqui, trata-se da noção de inclusão perpassada pela ideia de participação. Popkewitz (1998) afirma que, há pouco tempo, essa noção emergiu já nos Estados Unidos (EUA), com a administração das questões sociais pelo Estado, a partir de conceitos de democracia e capitalismo da burguesia europeia. Assim, trabalha-se com uma dupla questão: a inclusão e a exclusão; a igualdade e a desigualdade. As desigualdades sociais e raciais brasileiras têm, na estatística, a sua principal fonte de dados, sendo os mesmos utilizados para avaliação, planejamento e reivindicações: "O Censo oferece informações vitais para aqueles que têm a responsabilidade da gestão e planejamento local e útil aos cidadãos e às instituições para avaliar as políticas implementadas" (IBGE, 2010).

Assim, o instituto cumpre o postulado na Conferência de Durban, onde os países participantes foram "estimulados a coletarem, compilarem, analisarem, disseminarem e publicarem dados estatísticos confiáveis, em nível local e nacional, relativos a indivíduos e membros de grupos e comunidades sujeitos à discriminação" (FUNDAÇÃO PALMARES, 2007). A preocupação do governo no campo educacional, com a criação de políticas afirmativas, fica também evidenciada na questão específica com as comunidades quilombolas.

Popkewitz (2001) vê a "estatística como campo de produção e reprodução culturais, preocupado com a administração social da liberdade do indivíduo" (p. 121). Trata-se, então, de "esquadrinhar" a população, seja por raça/cor ou por alguma outra classificação, que, em dado momento histórico, seja elevada e decretada como condição de "urgência" nas pautas do governo. Ainda mais: ao se trabalhar a dimensão étnico-racial na escola atrelada às demais ações governamentais de inclusão social, ela passa a ganhar "ares de solução" das desigualdades sociais, econômicas e políticas do país. O governo entende que, para abordar tais questões no âmbito escolar, exigem-se mudanças no currículo e investimento na formação dos professores.

Produz-se, então, um modo de tratar a questão étnico-racial na formação de professores.

\subsection{DO PEDAGÓGICO}

Cabe ressaltar que, antes da promulgação da Lei 11.645/2008, o Ministério da Educação, na perspectiva de estabelecer "uma arquitetura institucional capaz de enfrentar as múltiplas dimensões da desigualdade educacional do país" (p. 12), criou a Secretaria de Educação Continuada, Alfabetização e Diversidade (SECAD). Ela surgiu com o desafio de desenvolver e implementar políticas de inclusão educacional, considerando as especificidades das desigualdades brasileiras e "assegurando o respeito e valorização dos múltiplos 
contornos da diversidade étnico-racial, cultural, de gênero, social, ambiental e regional brasileiras" (sic.).

A instituição da SEPPIR e da SECAD e a profícua parceria entre estas duas Secretarias está dada em diversas ações e programas e traduzem uma ampla conjugação de esforços em todo o país para a implementação de políticas públicas de combate à desigualdade. Participam também da formulação e desenvolvimento dessas políticas, a Secretaria de Políticas para Mulheres (SPM) e a Secretaria de Direitos Humanos (SEDH), e assim, diante dos diversos níveis de abordagens para o desenvolvimento da democracia participativa, com o fortalecimento dos importantes segmentos da sociedade organizada e de instituições outras que representam gestores educacionais, o Estado estabelece as bases para que políticas públicas de educação para a diversidade se tornem uma realidade no país, e fomenta sua continuidade construindo colaborativamente, com os mais diversos setores, as linhas de ação que anteveem uma maior abrangência em benefício dos cidadãos historicamente mais vulneráveis (Plano Nacional de Implementação das Diretrizes Curriculares Nacionais para a Educação das Relações ÉtnicoRaciais e Para o Ensino da História e Cultura Afro Brasileira e Africana (MEC, 2009, p. 15-6).

Com essa obrigatoriedade, o governo decretou um alerta de urgência para que as administradoras dos sistemas de ensino ofereçam formação continuada aos professores sobre a questão étnico-racial. Na legislação educacional, determina-se o reconhecimento dos direitos da população negra, afro-brasileira e indígena. O Plano Nacional de Implementação das Diretrizes Curriculares Nacionais (DCNs) para a Educação das Relações Étnico-Raciais e para o Ensino da História e Cultura Afro Brasileira e Africana, é outro documento oficial que reforça a necessidade e a urgência de implementar essas Diretrizes no país. O referido Plano foi apresentado como resultado da mobilização e esforço de várias instituições, dentre elas a UNESCO, a CONSED e a União Nacional dos Dirigentes Municipais (UNDIME), bem como da parceria de alguns Ministérios do próprio governo, da contribuição dos movimentos sociais e organizações de intelectuais e da sociedade civil (BRASIL, 2009, p. 9). O próprio documento explicita, em sua introdução, que "foi construído como um documento pedagógico com o intuito de orientar e balizar os sistemas de ensino e as instituições correlatas na implementação das Leis 10639/2003 e 11645/2008" (BRASIL, 2009, p. 12).

O Plano quer concretizar uma "ação orientada para o combate a todas as formas de preconceito, racismo e discriminação que porventura venham a se manifestar no ambiente escolar" e atribui ações aos sistemas de ensino da educação brasileira, nos âmbitos do governo federal, estadual e municipal (p. 12). Explicita, ainda, a importância do "apoio sistemático aos professores para elaboração de planos, projetos, seleção de conteúdos e métodos de ensino, cujo foco seja História e Cultura Afro-Brasileira e Africana, e a Educação das Relações Étnico-Raciais". Desse modo, a partir da criação de práticas políticas 
e pedagógicas de inclusão, legitimadas pelas práticas jurídicas, produziu-se, no discurso governamental, na escola e na formação de professores, um modo de tratar a temática étnico-racial. Cabe examinar, agora, as mudanças que estão ocorrendo no momento, seja na (e com a) formação de professores e sua relação com as práticas escolares.

Para perspectivar a formação de professores no cenário jurídico, político e pedagógico, é preciso, inicialmente, refutar a ideia de formação continuada como complementação das lacunas do currículo da formação inicial do professor, ou seja, como uma simples inserção de 'temas' como o racismo, o preconceito e a discriminação racial. Assuntos complexos, controversos, que carregam conceitos imbricados em séculos de uma história das relações entre negros e não negros, no Brasil, de uma história contada às avessas.

\section{CONSOLIDAÇÃO DAS POLIITICAS DE AÇÕES AFIRMATIVAS PARA A EDUCAÇÃO}

Desde a sua criação, em 2003, ficou estabelecido que a SEPPIR iria "assessorar direta e imediatamente o Presidente da República na formulação, coordenação e articulação de políticas e diretrizes para a promoção da igualdade racial [...]" (BRASIL, 2003). A partir daí, propôs-se uma forma de tratamento para a questão racial no cotidiano escolar. Ao estabelecer "novas diretrizes e recomendar práticas pedagógicas que reconheçam a importância dos africanos e afro-brasileiros no processo de formação nacional", o MEC justifica sua proposta de Formação Continuada como um auxílio aos professores na execução de tarefas, compartilhando, assim, do seu trabalho diário na consolidação dessa proposta.

Entendendo a própria SEPPIR, bem como suas ações, como um dispositivo de governo que trata, dentre outras coisas, da questão racial e suas implicações nas situações de preconceito e discriminação, vê-se que é remetido à escola e, de modo específico, ao professor, a tarefa de tratar a questão considerada "urgente e de abrangência social". Ou seja, tais dispositivos atuam como reguladores da escola, apontando quando (e como) tal questão deve ser tratada. Foucault (1979, p. 244) define "dispositivos" como sendo um conjunto decididamente heterogêneo, que engloba discurso, instituições, organizações arquitetônicas, decisões regulamentares, leis, medidas administrativas, enunciados científicos, proposições filosóficas, morais, filantrópicas. Em suma, o dito e o não dito são os elementos do dispositivo; é a rede que se pode estabelecer entre esses elementos.

Diante da variedade de dispositivos acionados pelo governo nas suas políticas de inclusão étnicoracial, é possível ver como se instituiu, na atualidade, a ideia de formação para a educação étnicoracial. Também é possível ver a força de imposição que recai sobre o processo atual de formação e suas diferentes significações no contexto educacional brasileiro. Sinalizam-se grandes mudanças que 
marcariam a educação brasileira, no sentido de respeito à diversidade e à tolerância, priorizando a cultura da paz, e os movimentos começariam com a capacitação dos professores, pois eles trabalham diretamente com crianças e jovens. Para a então ministra Matilde Ribeiro, da SEPPIR, os professores seriam os "propulsores deste processo".

O Ministério da Educação e Cultura, a SEPPIR, e a Secretaria de Alfabetização e Diversidade (SECAD) disponibilizam materiais para consulta e reprodução (nos sites oficiais do governo), distribuem livros paradidáticos e materiais audiovisuais a todas as escolas do país, oportunizam programas e projetos de formação para professores (nas modalidades presencial e à distância - em parceria com instituições formadoras) ${ }^{4}$, bem como promovem ações articuladas junto aos Ministérios da Cultura, Saúde, Desenvolvimento Social, dentre outros, além de outras organizações governamentais e nãogovernamentais. Quanto ao investimento do governo na disponibilização de materiais aos professores, destaca-se o lançamento de um dos primeiros livros da SECAD, ou seja, uma publicação com o selo oficial do MEC, com o objetivo de implementar a Lei 10.639/2003. No seu texto introdutório, há uma conclamação aos professores:

[...] nós, educadores (as) brasileiros(as), necessitamos urgentemente contemplar no interior das escolas a discussão acerca das relações raciais no Brasil, bem como de nossa diversidade racial. Nessa linha, é preciso não só boa vontade e sensibilidade dos profissionais da educação, mas também o fornecimento de material didáticopedagógico anti-racista (sic.) e recursos auxiliares aos professores para que possam ministrar aulas combatendo o preconceito e a discriminação raciais (BRASIL, 2005, p. 14, acréscimo meu).

Desse modo, ressaltam-se os comentários sobre o esforço da SECAD e do MEC, no sentido de uma educação democrática, sem preconceito, não eurocêntrica, enfim, inclusiva. Trata-se de uma intervenção governamental, um chamamento do Estado às escolas e professores, que acaba por inscrever a raça nos sistemas de ensino, colidindo de frente com "o movimento de ideias que produziu o conceito contemporâneo de direitos humanos" (MAGNOLI, 2009, p. 335). Assim, oficializa-se e estimula-se "a produção de materiais escolares que delineiam uma história racial do Brasil". Magnoli chama a atenção, ainda, sobre a forma como tais materiais são produzidos a partir da intervenção governamental, que oficializa e estimula a produção de materiais escolares, onde: "a maior parte dos autores destes materiais participam como militantes de uma causa, não como historiadores ou cientistas sociais". Também

\footnotetext{
4 Também foram realizados Fóruns Estaduais de Educação e Diversidade Étnico-Racial, organizados pela SECAD, em 2004, onde
} ocorreram parcerias com as Secretarias Estaduais de Educação, os Movimentos Sociais Negros e Universidades Federais. 
participam "das redes que conectam o mundo acadêmico às ONGs racialistas" (MAGNOLI, 2009, p. 335). Hélio Silva Junior (2001) traz a pergunta que não quer calar: "Há uma pergunta que vem sendo formulada por todas as correntes de pensamento: porque deveria haver políticas públicas especiais para negros descendentes?" (p. 308).

Paradoxalmente, porque deveria haver formação de professores para trabalhar a história dos negros e afrodescendentes? Ficam as perguntas ou mudam-se as perguntas: por que não? Há movimentos nos quais estudiosos, pesquisadores, e militantes do tema étnico-racial, partem em defesa da formação de professores como um dos únicos meios de transformação social, minimizando o preconceito e as desigualdades; minimizando, também, as graves questões sociais e econômicas, por meio do tratamento das desigualdades na escola. Uma vez, isto ficou conhecido como "otimismo pedagógico"!

Ao mostrar diferentes entendimentos das políticas de inclusão social e étnico-racial, a intenção não foi a de optar entre umas e outras, nem tampouco de apontar qual a melhor ou qual tem a argumentação mais consistente. 0 que se propõe (mesmo que seja pretensioso demais) é ver a formação de professores como uma estratégia do governo que, por isso mesmo, nos interpela em todos os momentos. Sobretudo, como agora, encarregada de tratar das desigualdades raciais e sociais produzidas ao longo do processo histórico brasileiro. Tais interpelações são, no mínimo, perturbadoras, em tempos de discursos democráticos sobre a (des) igualdade de raças e de etnias.

\subsection{DIRETRIZES CURRICULARES NACIONAIS (DCNS) PARA A EDUCAÇÃO DAS RELAÇÕES ÉTNICO-RACIAIS}

A Resolução CNE n 1, de 17 de junho de 20045', estabelece as Diretrizes Curriculares Nacionais para a Educação das Relações Étnico-Raciais e para o Ensino da História e Cultura Afro-Brasileira e Africana. Ou seja, a forma de tratamento das temáticas que dizem respeito aos negros e afrodescendentes são abordadas no sentido de garantir a inserção do assunto nos currículos, tanto da educação básica quanto do Ensino superior, como pode se observar abaixo:

Art. $1^{\circ}$ A presente Resolução institui Diretrizes Curriculares Nacionais para a

Educação das Relações Étnico-Raciais e para o Ensino de História e Cultura AfroBrasileira e Africana, a serem observadas pelas Instituições de ensino, que atuam nos níveis e modalidades da Educação Brasileira e, em especial, por Instituições que desenvolvem programas de formação inicial e continuada de professores. $\S 1^{\circ}$ As

\footnotetext{
${ }^{5}$ Conselho Nacional de Educação (CNE) e Conselho Pleno (CP). Resolução n 1, DE 17 de junho de 2004, institui as Diretrizes Cur-
} riculares Nacionais para a Educação das Relações Étnico-Raciais e para o Ensino de História e Cultura Afro-Brasileira e Africana. 
Instituições de Ensino Superior incluirão, nos conteúdos de disciplinas e atividades curriculares dos cursos que ministram, a Educação das Relações Étnico-Raciais, bem como o tratamento de questões e temáticas que dizem respeito aos afrodescendentes, nos termos explicitados no Parecer CNE/CP 3/2004. $\S 2^{\circ} 0$ cumprimento das referidas Diretrizes Curriculares, por parte das instituições de ensino, será considerado na avaliação das condições de funcionamento do estabelecimento (BRASIL, 2004).

Essas diretrizes partem do princípio de que o professor precisa apropriar-se dos conhecimentos sobre as culturas negra e indígena para ensiná-los na escola. Nesse sentido, nas discussões sobre os problemas da qualidade do ensino e da formação de professores, o tema passa a ter maior visibilidade, na tentativa de assegurar a igualdade racial apontada na Constituição de 1988. É importante salientar, aqui, a reafirmação do discurso de mudanças sociais via escola. Tais aspectos "salvacionistas" pressupõem que um professor, com ampla capacitação sobre as questões do negro e do índio, seja capaz de minimizar ou erradicar as questões de preconceito e discriminação. A Resolução, na esteira dos demais documentos oficiais, implica a existência de raças, e esclarece que não se trata do "racismo científico", mas dos conceitos da Sociologia e da Antropologia. Como trabalhar, na escola, a erradicação do preconceito e da discriminação, com base neste pressuposto de que raças existem como um constructo social?

Desde a alteração da LDB, em 2003, através da Lei 10.639/2003, que inclui a questão étnico-racial no currículo escolar, e também da Resolução n 1/2004, do Conselho Nacional de Educação, que institui as Diretrizes Curriculares Nacionais para a Educação das Relações Étnico-Raciais, percebe-se um amplo movimento com diferentes ações do governo via Secretaria da Diversidade (SECADI), no sentido de implementação dessa legislação na educação básica, a nível nacional. Este movimento abrange os princípios que devem conduzir as ações dos sistemas de ensino, dos estabelecimentos, e dos professores. São eles: consciência política e histórica da diversidade, fortalecimento de identidades e direitos, ações educativas de combate ao racismo e discriminações. Um exemplo de mobilização para implementação das Diretrizes é a Universidade Federal do Rio Grande do Sul, com o trabalho do Departamento de Educação e Desenvolvimento Social (DEDS), que se consolidou como um dos locais de divulgação e articulação, desde a publicação do documento pelo CNE. A partir de 2003, o DEDS criou o Programa de Educação Antirracista no Cotidiano Escolar e Acadêmico e, desde então, vem executando projetos voltados à formação de professores, em parcerias, sobretudo, com as secretarias municipais de educação da região metropolitana de Porto Alegre (UFRGS, 2008, p. 2).

Desse modo, o Estatuto da Igualdade Racial (2005), de autoria do senador Paulo Paim, é também um documento que reforça o modo de tratamento da questão étnico-racial no país e suas orientações não se restringem à área educacional. O Estatuto foi aprovado após dez anos tramitando no Congresso Nacional, 
sancionado com inúmeras alterações, e traz, em seu parágrafo VII, a emergência da implementação de programas de ação afirmativa para o enfrentamento das desigualdades raciais no âmbito social, educacional, cultural, esportivo, jurídico, etc (BRASIL, 2005).

Aos gestores públicos da educação são colocados desafios, tais como sensibilizar e capacitar todos os profissionais da escola, visando comprometê-los com as mudanças que se fazem necessárias no currículo escolar, relacionando-as com as questões de diversidade cultural e étnico-racial. Esta determinação tem tornado as práticas escolares menos racistas e discriminatórias? Pelo contingente de professores que demanda a educação básica do país, talvez resida aí o maior desafio dos gestores educacionais: a implementação das DCNS na pauta das ações afirmativas na educação. Como propor programas de formação de professores que contemplem a questão étnico-racial e produzir mudanças nas práticas escolares? O discurso sobre a formação produz que tipo de professores? Que efeitos são produzidos na escola a partir da formação de professores?

\section{AS ATUAIS POLÍTICAS DE FORMAÇÃO DE PROFESSORES, SEUS PROGRAMAS E PROPOSTAS NOS CURSOS DE FORMAÇÃO CONTINUADA}

Pensar sobre as atuais políticas públicas de formação de professores implica, também, pensar pelo menos na atual situação de formação docente para os diferentes níveis e modalidades de ensino, no movimento dos professores, na busca de formação, nos movimentos institucionais e não institucionais, na oferta de formação, nas alterações da legislação educacional e nas diretrizes curriculares no Brasil. As questões que envolvem a formação de professores têm uma longa trajetória, desde o século XVI, com o empirismo inicial, até chegar, no início do século XX, aos fundamentos "científicos" para o ato de ensinar.

Concomitante aos processos de urbanização e industrialização brasileiros, que ocorreram na década de 1930, houve também o aumento da escolaridade e, portanto, mais escolas e professores (GATTI, 2009, p. 9). Atualmente, a expansão da oferta de escolaridade provocou, ainda, a demanda de maior contingente de professores nos diferentes níveis do processo de escolarização. Por outro lado, há urgências inseridas pelas transformações sociais que atingem toda a sociedade e acabam por pressionar a escola, exigindo mudanças de "concepções e práticas educativas, que possam contribuir significativamente para a construção de uma sociedade mais justa, democrática e moderna". Tais aspectos apontam para mudanças no cenário da formação de professores (a legislação se impôs com uma novidade: a exigência de nível superior para atuação no magistério) (GATTI, 2009, p. 12). Essa urgência coloca para o governo a necessidade de desenvolver a formulação de políticas públicas da educação. Elas são fortemente influenciadas pelos compromissos governamentais brasileiros, assumidos com 
os organismos internacionais de financiamento, em especial o Banco Mundial (via Plano Nacional para o Desenvolvimento da Educação). Assim, podem-se destacar suas interferências na definição de prioridades e estratégias para a educação, entre elas as Políticas Públicas de Formação de Professores.

Em 2004, foi criada, no Brasil, a Rede Nacional de Formação Continuada de Professores, cujo principal objetivo é contribuir para a melhoria da formação dos professores e, consequentemente, dos alunos. O público-alvo da rede são professores de educação básica dos sistemas públicos de educação. Em 29 de janeiro de 2009 foi publicado o Decreto n 6.755 (BRASIL, 2009), que instituiu a Política Nacional de Formação de Magistério da Educação Básica e disciplina a atuação da Coordenação de Aperfeiçoamento de Pessoal de Nível Superior (CAPES) no fomento a programas de formação inicial e continuada. No referido decreto, destaca-se o Art. $2^{\circ}$, que remete à formação dos profissionais do magistério, reiterando a importância do compromisso com um projeto educacional de abrangência social, ética e política, que promova a consolidação dos princípios democráticos (GATTI, 2009). O relatório da UNESCO (2009), que também utiliza o referido decreto como referência, ao tratar da Política Nacional de Formação de Professores, indica como principal proposta a organização da formação inicial e continuada "dos profissionais do magistério para as redes públicas da educação básica" (art. 1%), e o apoio "à oferta e à expansão de cursos de formação inicial e continuada a profissionais do magistério, pelas instituições públicas de educação superior" (GATTI, 2009, p. 52), ambos em regime de colaboração entre União, Estados, Distrito Federal e Municípios.

No ano de 2010, novas instituições de ensino superior públicas, federais e estaduais, foram integradas à Rede Nacional de Formação de Professores, ampliando, assim, a oferta de cursos. Essas instituições, articulando-se entre si e com outras IES (Instituição de Ensino Superior), são responsáveis pela produção de materiais que orientam os cursos à distância e semipresenciais, com carga horária variável entre 60 e 220 horas. Assim, elas atuam em rede, para atender às necessidades e demandas do PAR (Plano de Ações Articuladas) dos sistemas de ensino. As áreas de formação são: Alfabetização e Linguagem, Educação Matemática e Científica, Ensino de Ciências Humanas e Sociais, Artes e Educação Física. Carvalho (2005), em um artigo publicado sobre a formação de professores, afirma:

[...] com relação à formação continuada, a revisão de literatura, realizada por Carvalho e Simões (2002b), aponta que, de modo geral, há uma recusa da formação continuada significando apenas treinamento, cursos, seminários, palestras etc., emergindo uma conceituação de formação continuada como processo que encontra a sua centralidade no agir dos educadores no cotidiano escolar (CARVALHO, 2005, p. 97).

Para Nóvoa (2004), um bom programa de formação continuada deve constituir um apoio à atividade docente, auxiliando o professor a fazer o melhor em seu trabalho: ser pertinente à atividade docente 
e representar uma melhoria significativa da capacidade pedagógica. O representante da UNESCO no Brasil, Vincent Defourny, ao escrever a introdução do Relatório elaborado pela própria instituição, sobre a formação de professores, coloca que o grande desafio da educação é:

[...] sem professores valorizados e continuamente qualificados, o direito a uma educação de qualidade para todos não será uma realidade em nosso país, o que pode retardar a consecução de metas de qualidade na educação, que são imprescindiveis para o desenvolvimento do país (apud GATTI, 2009).

O desafio perpassa a organização curricular, onde se constata um currículo escolar estruturado para o ensino de alunos muito idênticos numa sala de aula. Na formação de professores ocorre um processo semelhante, quando se elabora uma proposta formativa que abrange todas as regiões do país, embora sempre esteja presente a observação de respeito às peculiaridades locais. Ressalta-se, ainda, a importância da continuidade das políticas implementadas, sem as interrupções que, geralmente, têm ocorrido nas duas últimas décadas.

É necessário que os professores, de fato, se apropriem e incorporem em sua prática docente os resultados positivos obtidos nas capacitações (GATTI, 2009). Com esse entendimento, sem que ocorra essa apropriação, a formação não faria sentido aos professores. Desse modo, é oportuno perguntar o que constituiria um bom programa de formação continuada. A quais aspectos deverá referir-se? De modo geral, reafirma-se, insistentemente, a importância da formação de professores e a perspectiva de mudança no aluno, a partir da prática cotidiana do professor. A partir daí, como pensar a escola e a formação de professores no cenário das teorias racialistas? Pensar de outro modo, a docência e a formação docente, bem como os discursos racialistas, implica olhar para além daquilo que a modernidade inaugurou e está dado como verdade.

Aqui, há mudanças cruciais em relação à formação de professores: os programas voltados à "educação das relações étnico-raciais" 6 são orientadores para a busca da melhoria da educação no país; postulam a igualdade de oportunidades; dialogam com os movimentos sociais e especificam demandas, tais como as políticas afirmativas para a população negra e parda. Assim, o governo cria mecanismos para o combate ao preconceito e à discriminação.

Os diferentes documentos analisados para fins deste estudo mostram um ideal de escola como um espaço acolhedor, que valoriza as diferenças. Para Tardif e Lessard (2009),

${ }^{6} \mathrm{O}$ termo é utilizado na legislação pertinente e nos documentos oficiais do MEC (diretrizes, orientações, materiais didáticos, etc.). 
[...] os professores constituem, em razão do seu número e da função que desempenham, um dos mais importantes grupos ocupacionais e uma das principais peças da economia das sociedades modernas. Eles representam, juntamente com os profissionais da saúde, a principal carga orçamentária dos Estados nacionais, quer na perspectiva dos que se nutrem dos ideais de educação para a construção de uma sociedade justa na distribuição de seus bens e na preservação de valores de solidariedade e de coesão social, quer na perspectiva dos que se preocupam com a eficiência interna dos processos educativos e com a eficácia na preparação do aluno para participar das transformações em curso no mundo contemporâneo, a formação dos professores sobressai como fator relevante (apud GATTI, 2009, p. 15).

Certamente, os professores não podem ser tomados como os únicos responsáveis pelo tratamento de uma questão tão abrangente quanto polêmica, no âmbito escolar. Ao deslocar a "solução" da questão étnico-racial para a escola, sobretudo, para a formação de professores, consolida-se uma centralidade na figura do professor. Assim, produz-se determinado modelo de formação. Quais são as condições da profissão e da formação de professores, diante do desafio que thes é imposto, a nível governamental, pelas atuais políticas públicas de combate à discriminação e ao preconceito? Por que se pressupõe que, a partir de uma formação específica, o professor seja capaz de transformar o aluno e a realidade que o cerca? Nos estudos e documentos oficiais até aqui examinados, voltados ao tema "formação de professores", verificou-se que é recorrente a citação de três grandes metas: a) aprimoramento pessoal, b) desenvolvimento da carreira, c) melhoria da qualidade da Educação (detalhamentos no Relatório da UNESCO [2009], que enfatiza as metas acima mencionadas, no item: "Propósitos e Procedimentos Formativos").

Diante disso, a formação específica para trabalhar na escola a temática étnico-racial poderá ser considerada, pelos professores, apenas mais um tema obrigatório do currículo que não lhes confere sentido trabalhar em sala de aula. Sem discutir se o tema confere ou não sentido aos professores, o documento elaborado pelo MEC (2008), intitulado "Contribuições para implementação da Lei 10.639/2003"7, explicita ações do próprio Ministério e da Secretaria da Diversidade (SECAD), onde se reafirma a obrigatoriedade de abordar o tema na sala de aula e argumenta sobre a necessidade de "tratar a diversidade étnico-racial como um valor que deve estar presente no processo de ensino aprendizagem e avançar no enfrentamento das desigualdades existentes no espaço escolar [...]" (BRASIL, 2008, p.

\footnotetext{
7 Trata-se de documento elaborado pelo Grupo de Trabalho Interministerial, instituído por meio da Portaria Interministerial MEC/ MJ/SEPPIR, $n^{\circ} 605$ de 20 de maio de 2008, o objetivo de desenvolver uma proposta de Plano Nacional que estabeleça metas para a implementação da Lei 10.639/2003. O MEC segue investindo na produção e distribuição de materiais didático-pedagógicos.
} 
5). Desse modo, consta, no documento orientador das DCNs, um conjunto de estratégias que estão organizadas em seis eixos. Utilizando-se dessas estratégias, o MEC quer atingir seu principal objetivo: erradicar práticas discriminatórias e racistas já institucionalizadas. Os eixos 2 (política de formação) e 3 (política de materiais didáticos e paradidáticos), juntamente com a revisão da política curricular, são colocados como os mais relevantes para o estímulo, a indução e a execução da Lei 10.639/2003 (BRASIL, 2009, p. 22).

Visando cumprir tal propósito, o governo investiu nas seguintes ações: criação de Fóruns Estaduais e Comissão Técnica Específica para assessorar o MEC/SECAD; instituição do Programa Brasil Quilombola e a Formação de Professores; promoveu a publicação e produção de materiais referentes à implementação da Lei 10.639/2003; criou o Projeto a Cor da Cultura, e também um Concurso Nacional, com o objetivo de incentivar produções de materiais didático-pedagógicos. As ações mencionadas fazem parte (ou são complementares) das propostas de formação de professores, para alcançar os objetivos traçados pelo MEC, mostrando como o governo empregou estratégias específicas de investimentos na formação de docentes, dentre outros, por meio de parcerias e financiamentos. Destacam-se, ainda, as seguintes ações: Programa de Ações Afirmativas para a População Negra (UNIAFRO), com o qual as Instituições de Ensino Superior (IES) puderam conveniar, a fim de ofertar os cursos presenciais / semipresenciais em suas regiões, a saber: curso a distância Educação- Africanidades-Brasil, e Cartografia sobre Geografia Afro-brasileira e Africana (BRASIL, 2008, p. 17). Para garantir a implementação da Lei 10.639/2003, o MEC utilizou-se de outra estratégia governamental, a de implantação de programas e projetos em todas as suas secretarias, denominadas secretarias-fim (BRASIL, 2008, p. 54).

A exemplo de programas realizados, destaca-se a Pró-reitoria de extensão (Prorext), da UFRGS, que desenvolve Programas de Políticas de Ações Afirmativas. Para ser executora de programas antirracistas do MEC, a instituição participou do edital UNIAFRO/MEC, em 2009, para então realizar, desde o início, o curso "Procedimentos Didáticos Pedagógicos Aplicáveis em História e Cultura Afro-Brasileira, reafirmando o seu lugar formador de educadores da Educação Básica, no que se refere às questões sobre a diversidade (BITTENCOURT JR.; SABALLA, 2012, p. 3-5).

Nessa primeira edição, este foi organizado pelo DEDS, na modalidade semi-presencial, com duração de 200h, distribuídas em 8 meses. Participaram cerca de quinhentos professores e bibliotecários de instituições civis e integrantes do Movimento Negro. Estiveram envolvidas cento e cinquenta escolas das redes de ensino parceiras, tanto do município de Porto Alegre quanto da região metropolitana. Ao final do curso, duzentos e sessenta e quatro participantes foram certificados, dentre os quais, representantes das cidades de Novo Hamburgo, São Leopoldo e região do Vale do Sinos/RS. Os coordenadores designados 
pelas Secretarias de Educação (também cursistas) foram responsáveis pelo acompanhamento dos professores em sua respectiva rede de ensino. O DEDS constatou que os cursistas eram, em sua maioria, atuantes em sala de aula, sendo $70 \%$ nas séries iniciais e educação infantil; $15 \%$ no ensino médio e educação de jovens e adultos; $10 \%$ em atividade de gestão e supervisão, e 5\% em atividades como serventes, cozinheiros e atendente escolar. Do total, $68 \%$ informou não ter experiência com a temática étnico-racial (BITTENCOURT JR.; SABALLA, 2012, p. 3-4).

O programa do curso resultou na organização de um livro, uma espécie de relatório do curso: "Procedimentos Didático-Pedagógicos Aplicáveis em História e Cultura AfroBrasileira". A publicação, de 2012, traz o prefácio da professora Petronilha Gonçalves e Silva, acadêmica e militante do Movimento Negro, a qual salienta a importância da obra em sua temática, não apenas para os professores, mas também para as lideranças profissionais de outras áreas como a Saúde, o Direito e a Economia. Enfim, de pessoas empenhadas em "lutas por justiça social". A execução de "políticas curriculares - sobretudo daqueles que tratam da diversidade sociocultural da nossa sociedade, que buscam corrigir as desigualdades entre grupos e pessoas, não é de responsabilidade unicamente dos professores" (BITTENCOURT JR.; SABALLA, 2012, p. 10). O livro traz artigos elaborados pelos docentes e organizadores do curso, que abordam as suas respectivas temáticas; pelos assessores das SMEDs; e relatos de projetos e demais ações dos professores cursistas.

Desse modo, entende-se que as ações governamentais, ao serem tomadas como objetos de análise, não atuam de forma independente e autônoma, em relação aos acontecimentos históricos do período em que são implementadas. Por isso, são "fragmentárias e transformáveis", conforme Foucault (1979, p. $\mathrm{XI}$ ): são análises que dizem respeito a um tempo, no qual os discursos produzem determinados sujeitos. Portanto, a formação de professores, ao fazer parte de uma conjuntura histórica e política, relacionase diretamente com as transformações sociais, projetadas por leis e regulamentos e, nesse sentido, participa do disciplinamento do indivíduo e da produção de subjetividades.

\section{ALGUMAS CONSIDERAÇÕES}

As atuais políticas públicas de formação de professores, voltadas à educação étnico-racial, pretendem fazer de cada professor e, consequentemente, de cada aluno, um defensor da igualdade de direitos entre os cidadãos, minimizando ou erradicando, com suas práticas, o preconceito e a discriminação étnicoracial no cotidiano escolar e, mais amplamente, na sociedade. A partir daí, define-se um modo de trazer e tratar a questão racial na escola.

A preocupação governamental e a pressão dos movimentos sociais em implementar políticas de 
reparação às populações negra ou afrodescendentes e indígena, produz uma maneira de pensar o preconceito e a discriminação racial. Além do mais, atende ao esforço do governo em cumprir a agenda de compromissos internacionais, referentes ao tratamento da temática étnico-racial.

Mas é esta história - da formação de professores voltada à questão étnico-racial - que me fez estabelecer interessadamente um percurso, um dito sobre as coisas aqui escritas. Uma certeza: a de que não produzi "a verdade" sobre os acontecimentos narrados, mas, sim, pensar sobre eles, problematizálos. Desse modo, foi possivel compreender que o governo utiliza-se amplamente de mecanismos como as estatísticas para criar e manter suas políticas de intervenção junto à população; isolá-la por raça e cor é uma estratégia que facilita o controle dessa população da qual fazem parte os brancos, os negros, os pardos, os amarelos e os indígenas! As problematizações a que submeti a formação de professores - dos acontecimentos sobre (e na) formação de professores, tomados como campo de pesquisa traduziram a ideia de desprender-me do que já se pensava a respeito do assunto, numa busca de "pensar diferentemente".

Em relação à temática racial, nos documentos do MEC - SECAD, SEPPIR, programas que, tanto os objetivos quanto as orientações didáticas voltadas à formação de professores, remetem ao resgate e à valorização da história das diferentes etnias - no caso específico da Lei 10.639/2003, dos negros, pardos e afrodescendentes, ficou ressaltado o quanto ainda se faz necessária a abordagem da questão étnicoracial na sociedade, sobretudo na escola, no currículo escolar e na própria formação de professores.

Um dos aspectos mais abordados em toda a documentação examinada é de que as mesmas cumprem os objetivos das DCNs para a "educação das relações étnico-raciais", enfatizando o conhecimento da história da África, dos negros e dos afrodescendentes. Porém, entende-se que conhecer essa história não garante a minimização ou erradicação da discriminação e preconceito racial - das desigualdades raciais e sociais.

Foram séculos não de 'invisibilidade' dos negros e mestiços, mas de uma 'visibilidade' de negros e mestiços ainda no rastro do colonialismo, do negro e do mestiço como objeto / mercadoria. Outros tempos, outras cenas e cenários de uma história que não foi e nunca será contada por inteiro, e as lacunas dessa história (de todas!) também são discursos. Na esteira dessa narrativa, foram e são produzidas outras visibilidades dos negros, dos pardos e dos afrodescendentes, e o tempo histórico, o lugar, as relações, os sujeitos, os interesses, etc., hoje nos dão outros contornos dessa visibilidade. Mas e as lacunas dessa história? Veyne (1998), ao abordar a "natureza lacunar" da história, diz que:

O mais curioso é que as lacunas da história se fecham espontaneamente a nossos olhos 
e que só as discernimos com esforço, tanto são vagas as nossas idéias sobre o que devemos a priori esperar encontrar na história, como a abordamos desprovidos de um questionário elaborado. Um século é um branco nas nossas fontes, e o leitor mal sente a lacuna. 0 historiador pode dedicar dez páginas a um só dia e comprimir dez anos em dez linhas: o leitor confiará nele, como um bom romancista, e julgará que esses dez anos são vazios de eventos (p. 27).

Complexa é a trama trazida pelos discursos neste estudo sobre a formação de professores para a "educação das relações étnico-raciais". Constatou-se, nos documentos e nas ações implementadas, o esforço governamental, a fim de cumprir os compromissos assumidos internacionalmente na agenda de criação de políticas afirmativas para a população negra. O discurso da legislação, da política e o próprio discurso pedagógico, são capturados pela lógica dos números - pelo discurso das estatísticas. Desse modo, está posto na escola e na formação de professores o discurso de inclusão social, sendo este também que define os modos de oferta da formação para cumprir a Lei 10.639/2003 e seus desdobramentos nas demais políticas educacionais do país.

Retomo, ainda, que minha pretensão não é a de legitimar o que já sabia, mas colocar o objeto da pesquisa - a formação de professores - nesse outro lugar: o das coisas estranhas - mesmo já sendo familiares. Como diz Foucault (1984): "a viagem rejuvenesce as coisas, e envelhece a relação consigo" (p. 15).

\section{LISTA DE SIGLAS}

CEERT - Centro de Estudos das Relações de Trabalho e Desigualdade

CONSED - Conselho Nacional de Secretários de Educação

CNE - Conselho Nacional de Educação

DEDS - Departamento de Educação e Desenvolvimento Social

IBGE- Instituto Brasileiro de Geografia e Estatística

DCN - Diretrizes Curriculares Nacionais

LDB - Lei de Diretrizes e Bases da Educação Nacional

SECAD - Secretaria da Diversidade

SEPPIR - Secretaria de Políticas de Promoção da Igualdade Racial

SPM - Políticas para as Mulheres

SMED - Secretaria Municipal de Educação e Desporto

MEC - Ministério da Educação

UNESCO - Organização das Nações Unidas para a Educação, Ciência e Cultura 


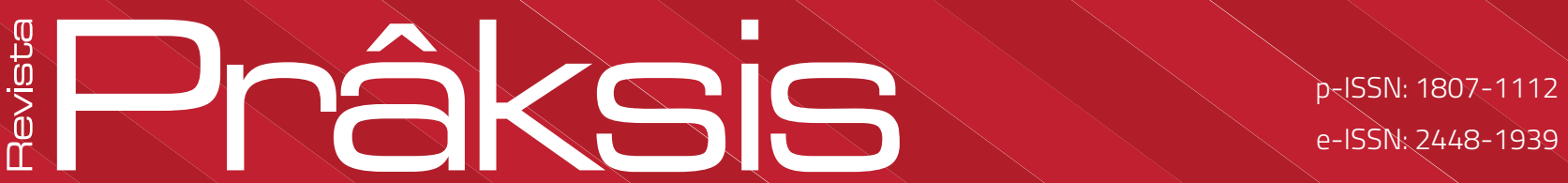

UNIAFRO - Programa de Ações Afirmativas para a População Negra

UNDIME - União Nacional dos Dirigentes Municipais

\section{REFERÊNCIAS}

ANSELMO. Eliane Regina Martins. Os parâmetros Curriculares Nacionais na Produção da Diferença

Racial. 2003. 124 f. Dissertação (Mestrado em Educação) - Universidade Federal do Rio Grande do Sul, Porto Alegre, RS, 2003.

BITTENCOURT JR. Iosvaldir Carvalho. Viviane Adriana SABALLA. Procedimentos Didático-Pedagógicos Aplicáveis em História e Cultura Afro-Brasileira. Porto Alegre: Editora da UFRGS. 2012.

BRASIL. Lei n 9.394, de 20 de dezembro de 1996. Estabelece as Diretrizes Bases da Educação Nacional. Diário Oficial da República Federativa do Brasil, Brasília, v. 134, n. 248, 23 dez. 1996. Seção I, p. 27834-27841.

Lei $\mathbf{n}^{\circ}$ 10.639, de 09 de janeiro de 2003. Altera a Lei $n^{\circ}$ 9.394, de 20 de dezembro de 1996, que estabelece as Diretrizes e Bases da Educação Nacional, para incluir no Currículo Oficial da Rede de Ensino a obrigatoriedade da temática "História e Cultura Afro-Brasileira", e dá outras providências. Disponivel em: <http://www.planalto.gov.br/ccivil_03/leis/2003/l10.639.htm>. Acesso em: 12 out. 2012.

\section{Diretrizes Curriculares Nacionais para a Educação das Relações Étnico-raciais e para o}

Ensino da História e Cultura Afro-brasileira e Africana. Brasília, 2004. . Ministério da Cultura. Instituto de Patrimônio Histórico e Artístico Nacional. 0 negro no Rio Grande do Sul. Porto Alegre, 2005.

. Lei $\mathbf{n}^{\circ}$ 11.645, de 10 de março de 2008. Altera a Lei no 9.394, de 20 de dezembro de 1996, modificada pela Lei no 10.639, de 09 de janeiro de 2003, que estabelece as Diretrizes e Bases da Educação Nacional, para incluir no Currículo Oficial da Rede de Ensino a obrigatoriedade da temática "História e Cultura. Brasileira e Indígena". Disponível em: <http://www.planalto.gov.br/ccivil_03/_ ato2007 2010/2008/lei//11645.htm>. Acesso em: 12 out. 2012. 


\section{. Plano Nacional de Implementação das Diretrizes Curriculares Nacionais para a Educação}

Étnico-racial e para o Ensino de História e Cultura Afro-brasileira e Africana. Brasília, 2009.

CARVALHO. Janete Magalhães. O Não-lugar dos Professores nos Entrelugares de Formação Continuada.

Rev. Bras. Educ, n. 28, Rio de Janeiro, jan./abr., 2005. Disponivel em: <http://dx.doi.org/10.1590/

S141324782005000100008>. Acesso em: 12 out. 2013.

DREYFUS, L. Hubert. RABINOW, Paul. O Sujeito e o Poder. In . Michel Foucault - Uma

Trajetória Filosófica: para além do estruturalismo e da hermenêutica. Rio de Janeiro:

Forense Universitária, 1995. p. 231-249.

SILVEIRA. Oliveira. O Muro. In: COLIMA. Paulo (Org.). Antologia da Poesia Negra Brasileira. São Paulo: Global editora, 1982. 103 p.

Transmissão. In: COLIMA. Paulo (Org.). Antologia da Poesia Negra Brasileira. São Paulo: Global Editora, 1982. 103 p.

FOUCAULT, Michel. Segurança, Território, População: curso dado no Collège de France (1977-1978). São Paulo: Martins Fontes, 2009 (Coleção Tópicos).

GATTI, Bernadete Angelina; BARRETO, Elba Siqueira de Sá (Org.). Professores do Brasil: impasses e desafios. Disponível em: <http://unesdoc.unesco.org/images/0018/001846/ 184682por.pdf>. Acesso em: 10 set. 2012.

INSTITUTO BRASILEIRO DE GEOGRAFIA E ESTATÍSTICA - IBGE. Sistema IBGE de Recuperação Automática: SIDRA. Disponível em: <www.sidra.ibge.gov.br/ bda/tabela/protab.asp >. Acesso em: 08 ago. 2014.

. Características Étnico-Raciais da População: um estudo das Categorias de Classificação de Cor ou Raça 2008. Rio de Janeiro: IBGE, 2011.

MAGNOLI, Demétrio. Uma Gota de Sangue: história do pensamento racial. São Paulo: Contexto, 2009. NÓVOA, Antônio (Entrevista concedida por e-mail, em outubro de 2004, ao CRE Mario Covas / SEE $\mathrm{SP})$.

PAHIM, Paulo. Estatuto da Igualdade Racial. Brasília: Senado Federal, 2003. 
PARFOR: Formação de Professores. Disponivel em: <www.observatoriodopne.org.br/noticias/parforformacao-desencontrada>. Acesso em: 20 out. 2012.

POPKEWITZ, Tom; LINDBLAD, Sverker. Estatísticas Educacionais como um Sistema de Razão: relação entre governo da educação e inclusão e exclusão social. Educação \& Sociedade, a. XXII, n. 75, ago. 2001. Disponivel em: <http://www.scielo.br/pdf/es/v22n75/22n75a08.pdf>. Acesso em: 15 fev. 2013.

POUTIGNAT, Philipe; STREIF - FENART, Joselyne. Teorias da Etnicidade. Seguido de grupos Étnicos e suas fronteiras de Fredrik Barth. São Paulo: UNESP, 1998.

PROJETO A COR DA CULTURA. Disponível em: <http://www.acordacultura.org.br/ pagina/ Kit\%20a\%20 Cor\%20da\%20>. Acesso em: 24 jul. de 2012.

SANTOS, Hélio. A Busca de um Caminho para o Brasil: a trilha do círculo vicioso. São Paulo: SENAC, 2001.

SALES, Augusto dos Santos. Educação Anti-racista: caminhos abertos pela Lei Federal n 10.639/03 A Lei $n^{\circ}$ 10.639/03, como fruto da luta anti-racista do Movimento Negro. SECADBrasília. 2005.

SOUZA, Edileuza Penha (Org.). Negritude, Cinema e Educação: caminhos para a implantação da Lei 10.639/2003. Vol. 2

VEYNE, Paul. Como se Escreve a História e Foucault Revoluciona a História. Brasília: UNB, 1998. 